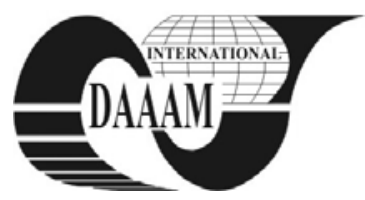

\title{
SHIPBOARD CRANKSHAFT BEARING IN-SITU REPAIRS UTILIZING LASER BUILD- UP WELDING
}

\author{
TORIMS, T[oms]; GERINS, E[riks]; RATKUS, A[ndris]; ZARINS, M[arcis] \& BRUTANS, V[aldis]
}

\begin{abstract}
When ship diesel engines are overhauled, the surface renovation of crankshaft bearings is of critical importance. Conventionally the crankshaft is removed from the engine and the subsequent build-up of bearing surfaces and grinding operations are performed in the workshop. New technology has been developed to perform crankshaft crankpin bearing surface grinding directly in the engine housing. This article outlines a further study confirming that the previously adopted grinding platform can be extended to fibre laser build-up welding technology. It is ideally suited to shipboard crankshaft surface renovation and opens up an entirely new dimension in laser build-up welding applications, which offers considerable economic benefits.

Key words: in-situ crankshaft renovation, laser build-up welding technology, thermal spray
\end{abstract}

\section{INTRODUCTION}

One of the major challenges when overhauling ship diesel engines is removing the crankshaft from the engine, as the entire engine has to be dismantled. The crankshaft is then taken to the workshop and its working surfaces are renovated and reshaped on stationary machines. To avoid this time consuming and costly process, innovative equipment has been developed for in-situ repair of crankshaft crankpin journals (Torims et al., 2009).

Although the surface grinding technology has been ascertained to be highly efficient and money-saving, it does not address damaged crankshaft surface material build-up solutions. Hence research will be undertaken on how to deploy thermal spray technologies in in-situ crankshaft repairs using this technologically proven equipment. The following conventional methods for shipboard crankshaft journal renovation are currently used in ship engine repair:

- TIG/MIG/MAG build-up welding

- plasma coating (welding and spraying)

- metal-plastics, e.g. Devcon Plastic Steel ${ }^{\circledR}$

- surface hardening and nitrating.

These surface refurbishing techniques are approved by most Ship Classification Societies, but are limited to use only within workshop (onshore) environments. Others can be applied for emergency repairs and only as a temporary solution. None of these technologies can be used fully on board the ship. A potential solution to the problem could be to fit new laser buildup surface renovation equipment on the platform used for insitu crankshaft grinding (see Fig. 1).

This platform is placed directly on the crankshaft bearing surface to be repaired and ensures a solid base. Theoretically, if one finds a way to fit a laser build-up welding head onto this platform, the crankshaft surface refurbishing, including buildup welding, can be achieved directly in the engine housing. In this case, repairs would logically be limited to the crankpin journals only. This would have enormous economic benefits and could be combined with an in-situ crankshaft grinding machine. Thus in order to achieve the aforementioned goals, a comprehensive feasibility study is needed. The initial step in this study is to review laser build-up welding know-how, which at first glance seems to be an excellent, tailor-made solution for shipboard crankshafts repairs.

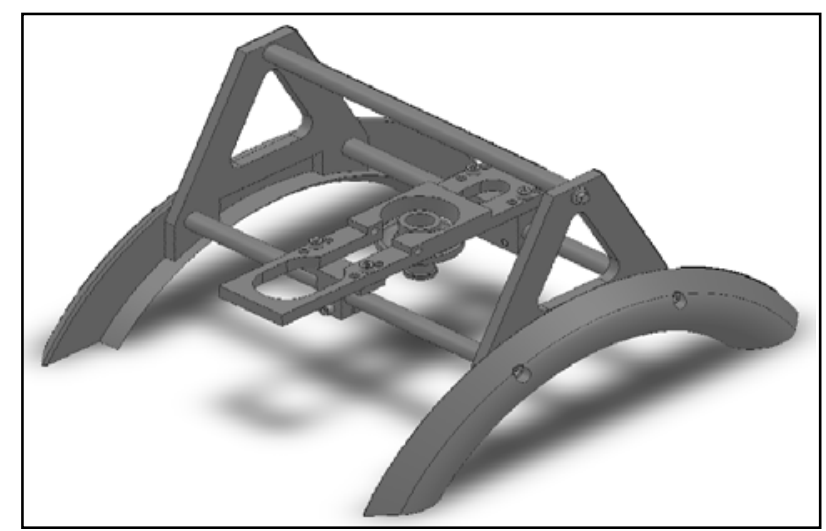

Fig. 1. In-situ crankshaft surface grinding machine platform

\section{LASER BUILD-UP WELDING TECHNOLOGY}

Laser beam build-up welding is technologically comparable to plasma build-up welding and plasma spraying. One of the advantages of this technology is its potential application in cases where the component is heavily stressed (e.g. crankshafts). Compared with conventional build-up welding, laser machinery distinguishes itself by the exact controllability of the welding process and composition of the layer, as well as the precise localization of the build-up material (Steen \& Mazumder, 2010).

The heat input into the workpiece is lower compared with MIG/MAG or plasma welding, whilst guaranteeing metallurgical bonding to the substrate. The accuracy of the resulting structures, in the range of $0.1 \mathrm{~mm}$, is the highest possible in the group of build-up welding techniques. On the other hand, the available system expertise (lasers, powder feeders and nozzles) permits easy, successful integration of the laser technology into manufacturing systems (Nowotny et al., 2007).

Laser beam welding uses a high-power laser beam as the source of heat to produce a fusion weld. Because the beam can be focused onto a very small area, it has a high energy density and deep penetrating capacity. The beam can be directed, shaped and focused precisely on the exact part of the workpiece. Laser beam welding provides good quality results with minimum shrinkage or distortion. Laser welds have good strength and are generally ductile and free of porosity (Kalpakjan \& Schmid, 2010).

Laser beam build-up welding is rapidly gaining ground in industrial manufacturing. The new fibre laser applications make it possible to reach difficult welding positions. Furthermore, a new compact coaxial powder nozzle for fibre laser build-up welding has been developed. This nozzle features in particular a 
compact design for improved accessibility and a smaller powder focus. The powder distribution within the nozzle is segmented into four, independent powder injectors. Thus the powder delivery becomes virtually independent of gravity. As a result, the nozzle can be used to perform build-up welding in any direction (IWS, 2011).

\section{APPLICATION OF THE TECHNOLOGY}

Several build-up welding laser platforms are currently already available on the market (IWS, 2011). Table 1 summarises the technological features and parameters of shipboard diesel engine crankshaft renovation needs.

\begin{tabular}{|c|c|}
\hline \multicolumn{2}{|c|}{ Maximal output power in KW } \\
\hline $\mathrm{CO}_{2}$ & 20 \\
Nd:YAG & 4 \\
Diode & 4 \\
\hline \multicolumn{2}{|c|}{ Surface layer geometry in a single operation } \\
/for a $6 \mathrm{~kW}-\mathrm{CO}_{2}$ laser/ \\
\hline \multicolumn{2}{|c|}{0.5 to $8 \mathrm{~mm}$} \\
built-up layer width $-l$ & 0.2 to $2 \mathrm{~mm}$ \\
built-up layer height $-h$ & 0.3 to $3 \mathrm{~mm}$ \\
single layer thickness $-b$ & up to $1 \mathrm{~kg} \mathrm{~h}^{-1}$ \\
deposition rate & reps \\
\hline
\end{tabular}

Table 1. Laser build-up welding technical parameters

The integration of coaxial powder nozzle onto the crankshaft in-situ renovation platform is illustrated in figure 2. The nozzle can be oriented manually and/or mechanically. Sufficient accessibility has to be confirmed and there should be no "blank spots".

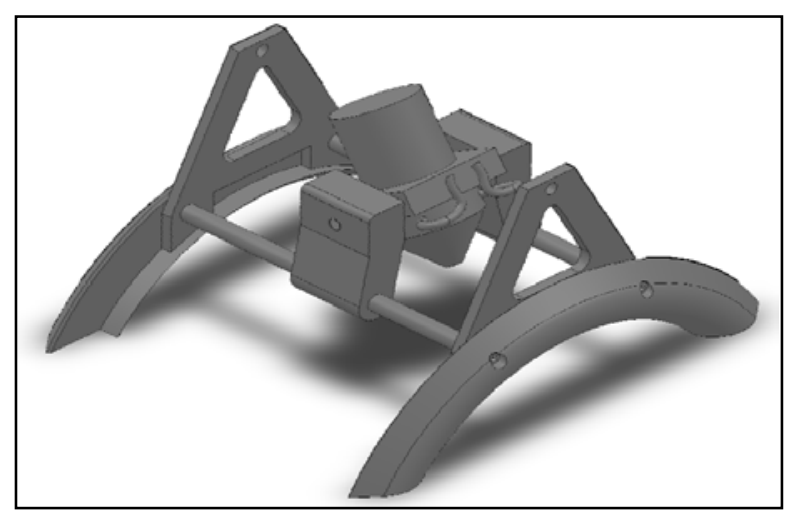

Fig. 2. Laser build-up welding machine prototype for shipboard diesel engine crankshaft bearing renovation

This technical solution cannot be applied to very small crankshafts owing to space limitations, or to very large diameters (max. $\varnothing 450 \mathrm{~mm}$ ). Already at the outset, there are clear advantages of such a technical solution: mobility, productivity, high surface quality with little finishing needed. Yet there are also certain problematic aspects and inherent difficulties:

- $\quad$ high initial cost of equipment

- highly qualified operators are needed

- $\quad$ high voltage power source (not a problem on vessel)

- separate station for welding powder or wire deposition.

An additional technical challenge is not to damage the technological platform during build-up welding operations. In practice, this means that particular attention should be taken so as to not touch the crankshaft bearing technological radiuses $R 8$ and $R 20$ and to allow a certain tolerance $-d$ (see Fig. 3).

Another aspect to bear in mind is that laser build-up welding of outer surfaces of bearings will be achieved at a certain angle - $\alpha$ and that respective laser power corrections will be needed to ensure homogenous deposition of the new surface layer(s). For crankshafts with external technological radiuses, subsequent manual application of some material might be needed to compensate "black" area left by the laser nozzle angle $\alpha$ (Fig. 3. a).

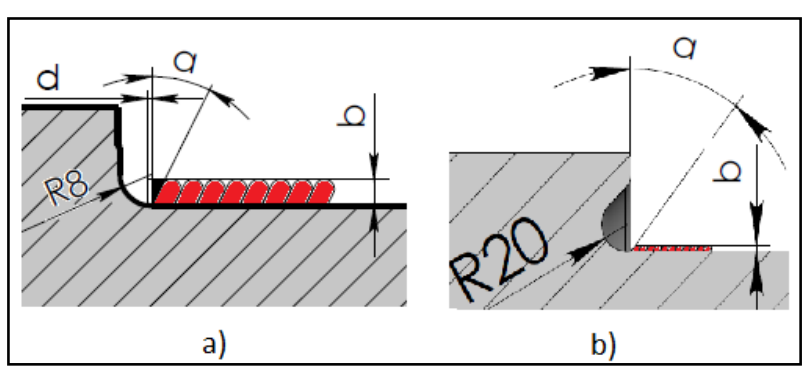

Fig. 3. Laser build-up material deposition model for crankshaft bearings of a) $\varnothing 120 \mathrm{~mm}$; b) $\varnothing 350 \mathrm{~mm}$

\section{CONCLUSION}

This article outlines an idea to use the laser build-up welding technique for shipboard engine crankshaft bearing surface repairs. It proposes to use the previously developed technological platform which is designed to perform renovation operations inside an engine. Theoretical study has confirmed that fibre laser build-up welding technology is ideal for shipboard crankshaft surface renovation. Although some technical difficulties where identified, a machine for shipboard crankshaft bearing in-situ repairs using laser build-up welding could be built. Study also revealed that this know-how can be applied to crankshafts with bearing diameters from 120 to 450 $\mathrm{mm}$. If constructed, tested and approved by the competent authorities, such a device would offer an innovative solution for shipboard crankshaft repairs. It opens up a new field of application to laser build-up welding and would generate considerable economic benefits.

In order to confirm this initial study, the prototype machine will be built and tested first in laboratory and then in-situ on board the ship. These initial tests should focus on verifying the surface quality and integrity obtained. Economic costs and practical factors also have to be further scrutinized.

\section{ACKNOWLEDGEMENTS}

This work was supported by the ESF, under Project Nr. 2009/0201/1DP/1.1.1.2.0/09/APIA/VIAA/112

"Nanotechnological research of the mechanical element surface and internal structure in mechanical engineering”.

\section{REFERENCES}

Fraunhofer Institute for Material and Beam Technology, IWS Dresden. (2011). Laser Beam Build-up Welding, Available from: www.iws.fraunhofer.de Accessed: 2011-08-11

Kalpakjan, S.; Schmid, S (2010). Manufacturing Engineering and Technology: 6th edition. Prentice Hall, ISBN 978-013-608168-5, Upper Saddle River, New Jersey, USA

Nowotny, S. (2007). Laser Beam Build-Up Welding: Precision in Repair, Surface Cladding, and Direct 3D Metal Deposition. Journal of Thermal Spray Technology, Vol.16, No.3,Sept.2007.pp344-348, DOI: 10.1007/s1166600790285 Steen, W \& Mazumder, J. (2010) Laser Material Processing, Springer, ISBN 978-1-8499-6061-8, New York, USA

Torims, T.; et al. (2009). New Approach for the Crankshafts Grinding and Determination of the 3D Surface Roughness Model for the Crankshafts Bearings, Annals of DAAAM for 2009 \& Proceedings of the 20th International DAAAM Symposium, ISBN 9783901509704, pp 1563-1565, Editor Katalinic, B., Published by DAAAM International, Vienna, Austria 